\title{
perifèria
}

Número 19 (1), Juny 2014

revistes.uab.cat/periferia

\section{Desafios do acolhimento e práticas espaciais: cotidiano da implementação de uma política pública nas bibliotecas dos Centros Educacionais Unificados (CEUs) de São Paulo}

Vinícius Spira - Universidade de São Paulo

\section{Resumo}

Os Centros Educacionais Unificados (CEUs), construídos a partir de 2003 em 45 pontos dos distritos mais pobres e desfavorecidos do município de São Paulo, oferecem uma combinação de equipamentos educacionais, culturais e esportivos. Este artigo apresenta resultados parciais de minha pesquisa de mestrado e reflete sobre a relação entre espaço e política, indo além da associação consagrada entre abertura espacial e democracia. O artigo propõe, também, pensar em termos de combinações de contextos extensivos, intensivos e separadores. Para isso, realizo uma análise comparada do cotidiano das bibliotecas de dois CEUs, utilizando etnografia e modelos virtuais.

Palavras-chave: antropologia organizacional, bibliotecas, etnografia, modelos virtuais.

\begin{abstract}
The Unified Educational Centers (CEUs), built since 2003 in many of the most poor and peripheral neighborhoods of São Paulo municipality, offer a combination of educational, cultural and sporting facilities. This article is part of a broader research conducted as a master dissertation, in which I go beyond univocal associations between space and politics - like the one that relates openness with democracy and propose the concepts of separational, intensive and extensive contexts. In order to do so, I do a comparative analisys of two CEUs' libraries, making use of ethnography and virtual models.
\end{abstract}

Keywords: organizational anthropology, libraries, ethnography, virtual models. 


\section{perifèria}

Número 19 (1), Juny 2014

Introdução

\section{revistes.uab.cat/periferia}

Iniciados pela gestão municipal de Marta Suplicy em São Paulo (2001-2004) e continuados nas gestões subsequentes de José Serra (2005-2006) e Gilberto Kassab (2006-2012), os CEUs inserem-se numa linhagem histórica de políticas públicas ${ }^{1}$ voltadas à implementação de equipamentos de grande porte em meio a bairros com alta concentração de pobreza e carências em geral. Esses equipamentos focam a dimensão pedagógica, mas não se restringem a atender às escolas no interior dos próprios CEUs ou em seu entorno urbano: oferecem, também, uma ampla gama de atividades de cunho cultural, esportivo e de lazer ${ }^{2}$ a todos os moradores da região.

O ideário do educador Paulo Freire é uma referência central para entender a concepção e implementação dos CEUs. Em resumo, a pedagogia freiriana declara-se crítica de práticas de ensino "tradicionais" ou "autoritárias", defendendo uma relação de simetria de poder entre alunos, e entre estes e os professores. Em outras palavras, uma educação feita em um espírito de cooperação, convívio e solidariedade, na qual a visão de mundo dos educandos é o ponto de partida para uma prática pedagógica que procura despertar o seu interesse, em vez de impor-se a eles. Nesse contexto, ninguém ensinaria ninguém, mas todos aprenderiam e construiriam conhecimento em conjunto (Freire, 1968).

Nos CEUs, o ideário freiriano encontra modos diversos de proliferar-se e afinidades com outras disposições, advindas de políticos, bibliotecários, arquitetos, produtores culturais, entre outros. Proliferações e afinidades difíceis de acompanhar, mas flagráveis, aqui e ali, sob a roupagem de discursos ora específicos, ora gerais; ora novos, ora consagrados.

No plano político-governamental, por exemplo, os CEUs foram idealizados dentro de um esforço por descentralizar a gestão do poder municipal. Nesse sentido, destacase sobretudo a implementação de Conselhos Gestores capaz de articular horizontalmente usuários e funcionários em nível local, numa concepção de gestão

1 Nessa linhagem destacam-se dois projetos anteriores: o sistema Escolas-classe/Escola-parque, desenvolvido na Salvador dos anos 1950 por um dos educadores mais importantes do Brasil, Anísio Teixeira; e os CIEPs, construídos nos anos 1980 e 1990 no estado do Rio de Janeiro, durante a gestão de Leonel Brizola, com participação do educador e antropólogo Darcy Ribeiro e do arquiteto Oscar Niemeyer.

2 Os CEUs abrigam os seguintes equipamentos: CEI (Centro de Educação Infantil), EMEI e EMEF (Escolas Municipais de Educação Infantil e de Ensino Fundamental), telecentro (sala de informática), teatro, ginásio de esportes, biblioteca, piscinas, ateliês, estúdios, sala de dança, padaria-escola, pista de skate e outros equipamentos de lazer externo que variam em função das condições de cada terreno (Padilha \& Silva, 2004). Em muitos CEUs há também uma EJA (Escola de Jovens e Adultos) e uma ETEC (Escola Técnica Estadual). 


\section{perifèria}

Número 19 (1), Juny 2014

\section{revistes.uab.cat/periferia}

participativa do equipamento público interessada em delegar poder para as pontas da máquina estatal, ou seja, onde as políticas são efetivamente entregues.

Quanto a questões relativas ao espaço, o projeto inicial de arquitetura dos CEUs encontra afinidade com a máxima freiriana segundo a qual para educar para a liberdade é preciso educar na liberdade. Assim, a promoção da abertura espacial seria não apenas um lema pedagógico e um elemento essencial da poética do CEU, como também um fator fundamental para sua constituição como um local de encontro, como uma centralidade urbana, enfim, como um espaço público e democrático destinado ao convívio de todos.

Neste texto, utilizo o termo acolhimento entre os níveis êmico e ético (Geertz, 1983) para fazer referência a essas ideias e práticas afins que não necessariamente possuem uma origem comum, mas que visam a uma intenção geral que orientou e continua a orientar o cotidiano da implementação da política pública dos CEUs. 0 termo é usado por muitos servidores públicos envolvidos com o cotidiano desses equipamentos e parece capaz de aludir a essa preocupação difusa para com o incentivo à simetria de poder, aos laços horizontais e ao convívio, ajustados às especificidades dos contextos periféricos e carentes em que se encontram.

O acolhimento ganha colorações e intensidades diversas conforme a situação considerada. Ele pode existir, por exemplo, de um modo declarado e bem delimitado, como em muitas das práticas cotidianas do CEU Butantã, em geral, e de sua biblioteca, em particular. Pode ser menos evidente e mais difundido em meio a outros valores e práticas, como no caso de muitos lugares do CEU Vila Rubi, e também de sua biblioteca. Neste trabalho realizaremos uma análise comparativa dessas duas bibliotecas, empregando a perspectiva etnográfica para iluminar alguns dilemas e contradições imprevistos, relacionados à implantação do programa do acolhimento. Nosso foco recairá na identificação de influências espaciais - dentre outras, análogas ao âmbito do espaço - na promoção do acolhimento.

\section{CEUs Butantã e Vila Rubi: contradições entre programas e práticas ${ }^{3}$}

O CEU Butantã está entre os mais conhecidos e antigos da cidade. Em relatos de antigos moradores e funcionários, o cotidiano desse equipamento entre setembro

3 o material etnográfico para este artigo foi coletado ao longo de aproximadamente 80 visitas de campo ao CEU Butantã e 30 ao CEU Vila Rubi, durante os quatro últimos anos, e especialmente em 2013. Conversas com bibliotecárias destacam-se em meio a registros de interações diversas que travei com usuários e funcionários dos CEUs em geral. Os diários de campo foram organizados em fichas eletrônicas com a utilização do programa Bento, e mais tarde com o programa NVivo, este último dedicado a facilitar codificações e análises de conteúdo. 


\section{perifèria}

Número 19 (1), Juny 2014

revistes.uab.cat/periferia

de 2003, quando foi inaugurado, e o fim de 2004, quando termina a gestão petista de Marta Suplicy, aparece como marcado por inúmeras atividades e visitações. Quadras de esporte e pista de skate lotadas até altas horas, aulas de música, conselho gestor ativo, reuniões que se prolongavam pela madrugada. No início da gestão de José Serra, em 2005, relatos dão conta de uma piora significativa na qualidade e quantidade de serviços oferecidos. Novos funcionários comissionados assumiram os postos de comando, e teriam se orientado por disposições e valores não alinhados com a priorização do acolhimento. A quantidade de recursos e funcionários reduziu-se bastante, instrumentos musicais mais caros permaneceram trancados em armários por muitos anos, reuniões de conselho esvaziaram-se e surgiram animosidades importantes entre funcionários, entre os equipamentos que formam o CEU, e entre o CEU e as próprias comunidades do entorno. Grande parte da comunidade teria se retirado do CEU; teria havido um esvaziamento de seus espaços que parece haver perdurado até recentemente. Nesse cenário, a dimensão espacial do acolhimento foi a que mais resistiu, certamente devido à resiliência natural das construções, de modo que os espaços amplos e abertos do CEU permaneciam relativamente preservados.

No esboço a seguir, podemos ver como o acolhimento está presente na poética de arquitetura que inspirou os 21 CEUs erigidos pela gestão Marta Suplicy, e que, como já dissemos, elegeu como um de seus temas centrais a promoção da abertura espacial:

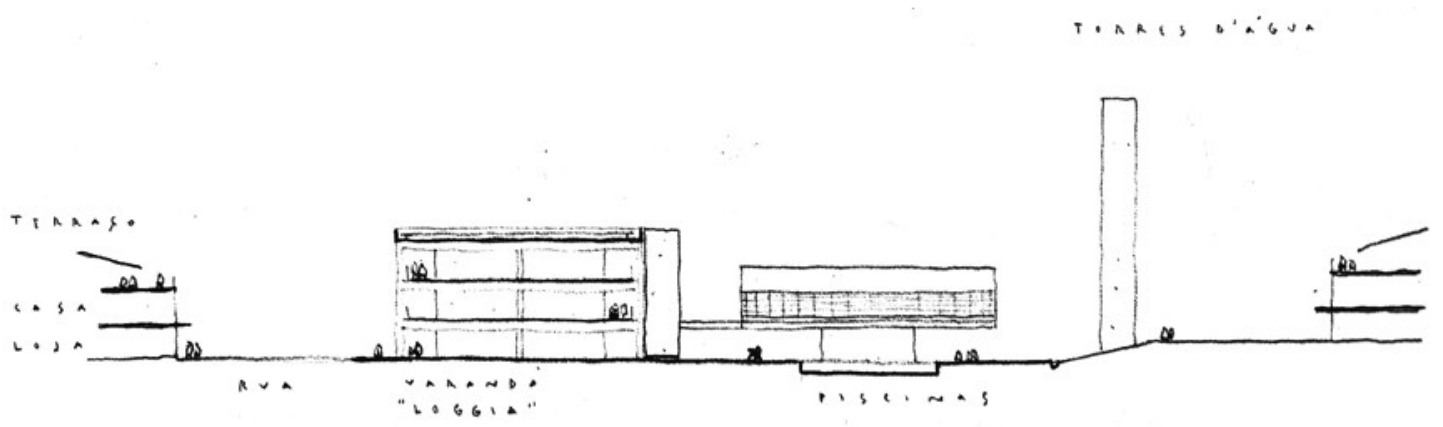

Figura 1: croqui explicativo dos CEUs construídos pela gestão Marta Suplicy (Doria, 2007).

Vemos aí grupos de pessoas distribuídas por diversos lugares do equipamento e das ruas e casas do entorno. Proliferam os contatos visuais. A fluidez do espaço é salientada pela ausência de quaisquer barreiras ou muros entre o CEU e a cidade, 


\section{perifèria}

Número 19 (1), Juny 2014

revistes.uab.cat/periferia

de modo a borrar propositalmente seus limites. Interessante notar que a abertura espacial é uma qualidade valorizada no campo da arquitetura mundial contemporânea, e entre muitos dos mais proeminentes arquitetos paulistas. Mais do que isso, a abertura espacial associa-se de um modo geral à ideia do livre acesso, à constituição de espaços públicos e à própria possibilidade de nossas democracias (Sennett, 1974:26; Ferraz, 1997:101; Caldeira, 2000; Williams, 2009; Dale \& Burrell, 2010).

Por sua vez, o CEU Vila Rubi foi criado em 2007 e é um dos 24 CEUs implementados durante as gestões de José Serra (2005-2006) e Gilberto Kassab (2006-2012). Desde sua criação, esse CEU foi administrado por funcionários indicados por políticos da coalizão que governou a cidade durante esse período de oito anos. As diretrizes que orientaram a gestão desse CEU são menos evidenciadas e menos evidentes, e a preocupação com o que temos chamado de acolhimento não se deixa entrever tanto quanto ocorre na atuação quase sempre mais veemente de servidores e funcionários ligados à esquerda do espectro político. Não há um alinhamento que coloque lado a lado bandeiras como a da pedagogia freiriana, a dos mecanismos de gestão participativa e a da abertura espacial. Os dilemas do acolhimento não são menos importantes, mas parecem derivar da própria necessidade do trato com as comunidades atendidas.

O projeto arquitetônico desse CEU, desenvolvido pela gestão de José Serra, orientou-se pela declarada intenção de contrapor-se à abertura espacial dos primeiros CEUs (Corbioli, 2008), prevendo muros e grades que procuraram conter e direcionar a circulação dos públicos pelos espaços. Além disso, o partido arquitetônico adotado tendeu a reduzir a quantidade de espaços disponíveis à livre circulação e ao convívio público. No CEU Vila Rubi em particular, esse fator acentuou-se devido à exiguidade do terreno em que foi instalado, equivalente a meio quarteirão urbano, sendo dez vezes menor que o terreno do CEU Butantã. A discrepância de áreas também acontece entre suas bibliotecas, como veremos.

Em contraste com essas características, foram criados, no CEU Vila Rubi, conselhos especificamente voltados a deliberar a respeito de iniciativas educacionais, culturais e esportivas, e passou-se a promover eventos culturais e festas temáticas que atraíram e atraem um grande contingente de moradores. Muitos funcionários ganharam os favores e o respeito da população, e certos moradores passaram a ajudar na organização e implementação de algumas ações. Esses fatos, se não evitam a presença de conflitos e animosidades, fazem predominar um clima de 


\title{
perifèria
}

Número 19 (1), Juny 2014

vivacidade e de acolhimento.

\author{
revistes.uab.cat/periferia
}

A história do CEU Butantã é marcada por concepções mais evidentes e mais articuladas de acolhimento, mas isso não garantiu uma relação intensa com as comunidades por ele atendidas. Um dos fatores para isso pode residir no vigor com que o valor do acolhimento foi defendido desde os primeiros anos dessa instituição, colocando-se em franca oposição a outras ideias e práticas que supostamente não se enquadram em seus termos, produzindo, assim, antagonismos importantes e difíceis de serem solucionados. Mesmo assim, a situação de esvaziamento do CEU Butantã é comumente apontada como a regra para a grande maioria dos CEUs. Por sua vez, a inserção da trajetória histórica do CEU Vila Rubi dentro de mandatos municipais que, como vimos, definitivamente não priorizaram o acolhimento é contraditada pela prolífica sociabilidade cotidiana que encontramos. Este é um dos importantes indícios que sugerem a situação deste CEU como uma exceção em relação aos outros.

Há, portanto, uma contradição entre programas e práticas, entre políticas públicas concebidas no alto escalão e o nível em que essas políticas são efetivamente implementadas e entregues. Uma segunda contradição refere-se à relação, nos dois CEUs, entre acolhimento e características espaciais: em termos esquemáticos, o CEU Butantã possuía espaços físicos abertos e espaços políticos fechados; o CEU Vila Rubi possuía espaços físicos fechados e espaços políticos abertos. Trata-se, portanto, de um material tentador para problematizarmos a relação entre espaço e política, e mais especificamente a relação entre abertura espacial e práticas democráticas, à qual já nos referimos anteriormente.

\section{Contextos separadores, intensivos e extensivos}

Começaremos com duas observações que procuram ilustrar a não vinculação necessária entre práticas democráticas e abertura espacial. Em primeiro lugar citamos as ações do gestor do CEU Vila Rubi quando do início da vida institucional do equipamento, período em que a unidade estava sendo depredada por comunidades que, ainda por cima, brigavam entre si. Ao implantar carteirinhas para o controle da entrada, e ao receber críticas por isso, o gestor alegou que não estava impedindo o acesso ao CEU, e sim protegendo quem estava lá dentro, para que "tivessem garantias". Numa reunião com lideranças comunitárias, disse-Ihes que do portão para fora "não podia fazer nada", mas que "do portão para dentro todos seriam tratados como cidadãos de direito". É muito significativo que, nesta fala, um 


\section{perifèria}

Número 19 (1), Juny 2014

revistes.uab.cat/periferia

dispositivo de controle do espaço - o portão - demarque justamente a possibilidade de efetivação da cidadania e não o seu cerceamento, como é mais comum ouvirmos. Os portões aparecem como garantidores de regras mínimas para um convívio respeitoso - e, portanto, como possibilitadores da vida pública, sobretudo diante da necessidade de conter frequentadores dispostos a brigar e a depredar as instalações do CEU.

Uma segunda observação sugere, por outro lado, que o espaço aberto nem sempre é sinônimo de práticas democráticas. No campo da antropologia organizacional, Dale \& Burrell (2010) mostram que, para contrapor-se às tradicionais conotações de hierarquia e status associadas aos espaços de trabalho corporativos fechados, tendências recentes têm defendido arranjos espaciais abertos e transparentes, acessíveis a todos os funcionários e com a finalidade de gerar um sentido de comunidade entre eles. Mas os autores refletem que, se essas mudanças têm produzido mais cooperação e comunicação, termina-se, em última instância, por favorecer os interesses das empresas, e não os dos funcionários. Acima de tudo, o espaço aberto dos novos ambientes corporativos permite monitorar e controlar mais facilmente os empregados, e não é à toa que a abertura espacial está presente também em interiores de prisões, ambientes fabris e outros lugares onde predominam assimetrias de poder.

Tudo isso sugere a necessidade de problematizar as análises que geralmente se contentam em vilanizar, indiscriminadamente, todo e qualquer fechamento de espaço. Um problema dessa tese é que ela trabalha com o falso pressuposto de que o espaço é capaz de influenciar a sociedade numa direção unívoca e necessária, como se os modos de apropriação e significação do espaço não tivessem uma parcela considerável de influência sobre as interações políticas cotidianas. Isto não quer dizer que as características objetivas do espaço sejam irrelevantes, mas que elas representam ferramentas que oferecem arcos de possibilidade de ação, como na analogia do martelo que serve para consertar ou machucar. Precisaríamos classificar as características espaciais em tipos que oferecem distintos leques de possibilidades de ação.

Adiantaremos aqui uma hipótese de resposta para esse problema, buscando inspiração em Warren (2010). Dentro de uma discussão sobre associações e democracia, esse autor se interessa em questionar a consagrada valorização das associações constituídas com base em laços voluntários, que, para a tradição toqueviliana, funcionariam como escolas de virtude capazes de preparar os 


\section{perifèria}

Número 19 (1), Juny 2014

revistes.uab.cat/periferia

indivíduos para o civismo e para a vida democrática. Warren sugere olhar não tanto para a facultação à entrada, mas para a facultação à saída, indicando que os conflitos internos às associações voluntárias tendem a ser resolvidos com a saída dos descontentes, segundo o lema de que as pessoas votam com seus pés. Com isso, associações voluntárias terminam por perder a possibilidade de produzir um entendimento coletivo em seu âmbito interno. Dentro da análise de Warren, grupos com laços voluntários acabariam por reunir membros com disposições similares em torno de consensos que produziriam, internamente ao grupo, um alto poder de mobilização e solidariedade, e, externamente, um mecanismo de reagregação de interesses de tipo mercadológico, produzindo vários grupos com membros dotados de interesses uniformes entre si. Por outro lado, grupos constituídos por laços não voluntários - tradicionalmente malvistos pela tradição toqueviliana - apresentariam uma maior pressão interna pelo poder de voz, gerando discussões e deliberações mais intensas, e uma menor univocidade de ação no nível grupal. Warren está preocupado em mostrar que laços não voluntários também podem ser positivos para a democracia, na medida em que desenvolvem em seus integrantes habilidades políticas e críticas que as associações voluntárias não estariam aptas a produzir.

A forma como a análise de Warren escapa ao maniqueísmo do binômio voluntário/não voluntário da tradição toqueviliana interessa para nós, mas os termos utilizados são conotativamente muito carregados e não fazem referência a alguns dos sentidos que gostaríamos de lhes dar. As noções de abertura ou fechamento também são muito carregadas pelo maniqueísmo das análises das configurações espaciais e urbanas que, por estarem concentradas apenas nos efeitos do cerceamento do espaço público e da democracia, falham em perceber outras consequências que não podem e não devem ser enquadradas univocamente dentro de uma chave desejável/indesejável.

Com base nessas discussões, propomos pensar em termos de contextos intensivos, extensivos e separadores para as análises que se seguem. O termo contexto faz referência a tudo que induz, com maior ou menor efetividade, as interações cotidianas entre agentes políticos. Além disso, contexto também é aqui usado para designar coisas que demoram para implantar-se, e que apresentam maior ou menor resistência à transformação imediata - em geral as práticas cotidianas precisam considerá-las como dadas, buscando adesão ou transposição, mas não eliminação ou transformação. Esta definição abarca as características espaciais como abertura/fechamento e amplitude/exiguidade, mas também um conjunto mais 


\section{perifèria}

Número 19 (1), Juny 2014

revistes.uab.cat/periferia

amplo de fatores, que envolve o nível de organização/desorganização do espaço, modos de disposição e uso de espaços, entre outros. Envolve também aspectos não espaciais, como normas de funcionamento, quantidade de recursos disponíveis, modos mais ou menos frequentes de avaliação etc. As análises que se seguem focarão nas dinâmicas espaciais e políticas que já viemos apresentando, mas sempre que for oportuno esses problemas serão conectados a partes desse espectro mais amplo de questões.

Resta apontar o que caracteriza um contexto como intensivo, extensivo ou separador. Um contexto extensivo indicaria a possibilidade de se optar ou não pelo estabelecimento de interações interpessoais, mas a liberdade daí decorrente também pode representar desincentivos ou ausência de incentivos para as interações, podendo produzir uma desaceleração da política. Falamos aqui de aspectos como: distâncias razoáveis entre ambientes de trabalho, fechamentos que dificultem mas não obstruam interações, aberturas que permitam afastamentos reversíveis, regulamentos que não prevejam prestações de contas.

Por sua vez, em contextos intensivos as interações interpessoais são induzidas pelas características do meio em que estão inseridas. Num certo sentido isso representa um cerceamento do poder de escolha das pessoas, mas em outro pode indicar a presença de aceleradores das interações: pequenas distâncias entre equipamentos e ambientes de trabalho, aberturas ou fechamentos de espaço que obriguem as pessoas a interagir, normas e avaliações que impliquem contatos frequentes entre as pessoas.

Finalmente, em contextos separadores as interações são impossibilitadas, intermitentes ou reguladas por dispositivos que não podem ser acionados por ninguém, ou que são acionáveis por apenas um dos lados da interação. Neste caso, falamos de portas, grades, paredes, distâncias excessivas entre pessoas e regulamentos que produzem clivagens de interesses e pessoas, características que podem estar associadas à produção de autonomia e privacidade, a reforços de subjetividade ou mesmo a garantias de assimetrias de poder.

Este trio de contextos organiza um conjunto exaustivo de efeitos políticos mutuamente excludentes: contextos extensivos possibilitam interações voluntárias; contextos intensivos e separadores estabelecem interações de tipo não voluntário, mas nos dois primeiros as interações são obrigatórias, enquanto no último elas são interrompidas. 


\section{perifèria}

Número 19 (1), Juny 2014

revistes.uab.cat/periferia

É importante ressaltar que esses conceitos encontram-se num nível muito alto de abstração. Eles passarão por especificações diversas, que terminarão por representar desafios significativos para um diagnóstico geral que afinal procurará encontrar, no CEU Butantã, o predomínio de contextos extensivos e, no CEU Vila Rubi, o predomínio de contextos intensivos.

Fica claro aqui que as características espaciais e legais não existem como realidades objetivas que independem do modo como são observadas pelas pessoas. Para muitos propósitos, o espaço não deve ser avaliado em termos absolutos e objetivos, e o fato de ser amplo ou exíguo, extensivo ou intensivo, depende, até certo ponto, do modo como é entendido e praticado pelas pessoas.

\section{Bibliotecas}

A biblioteca do CEU Butantã possui uma área de aproximadamente 500 metros quadrados. Suas laterais são amplamente envidraçadas, permitindo a entrada de luz e de olhares das imediações. Graças à posição central que ocupa no CEU, centenas de alunos passam, diariamente, à frente de sua porta e de suas vidraças. Apesar disso, a biblioteca encontrava-se quase vazia na maior parte do tempo, e replicava, ao seu próprio modo, as dinâmicas políticas que já vimos para o CEU Butantã como um todo. Os usuários do local resumiam-se a alguns frequentadores assíduos e a grupos de alunos das escolas do CEU, trazidos por professores para a realização de atividades curriculares. Saraus e exposições ocorriam com certa periodicidade, atraindo poucos interessados. Em seu corpo de funcionários, a biblioteca contava com uma coordenadora em cargo comissionado, que participara da implementação dos primeiros CEUs, sendo simpatizante declarada do acolhimento. Seguiam-se duas bibliotecárias com cargos efetivos, uma assistente técnica de ensino (ATE) e uma funcionária dedicada aos serviços de limpeza. Veremos como a sociabilidade entre esses servidores apareceu muitas vezes marcada por uma escolha dicotômica entre "usuários" e "livros", numa evidente especificação do tema do acolhimento. A perspectiva dos espaços da biblioteca, reproduzida a seguir, pretende funcionar em conjunto com as análises subsequentes. 


\section{perifèria}

Número 19 (1), Juny 2014

revistes.uab.cat/periferia

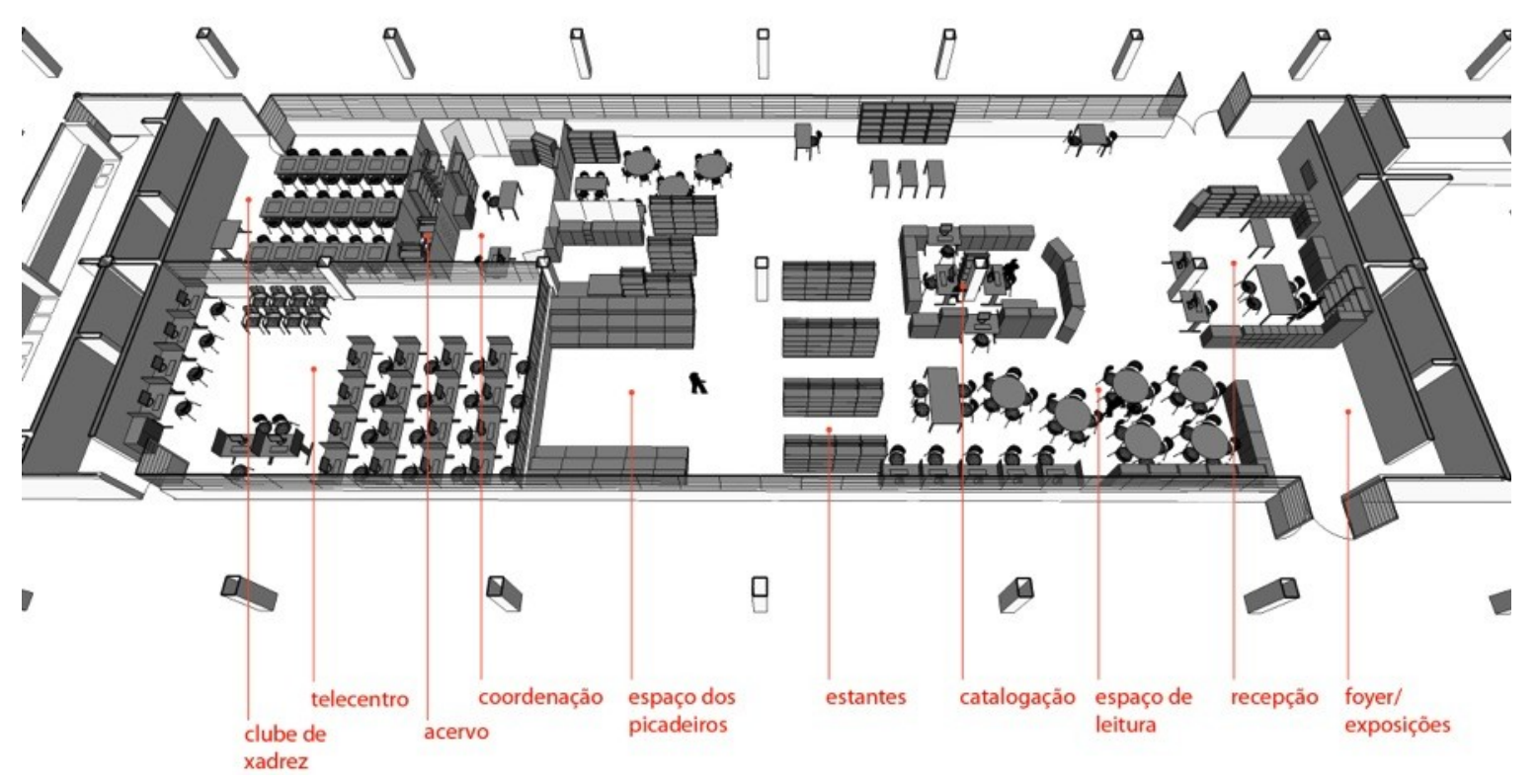

Figura 2: perspectiva da biblioteca do CEU Butantã.

Por sua vez, a biblioteca do CEU Vila Rubi possui uma área cinco vezes menor do que a do CEU Butantã, com aproximadamente 100 metros quadrados. Encontra-se no primeiro andar de um dos edifícios do CEU, mas isso não representa dificuldades de acesso, porque a proximidade espacial de outros equipamentos e públicos é considerável. Esta biblioteca era bastante utilizada, e promovia mensalmente cerca de dez eventos regulares, como oficinas de xadrez, mediações de leitura, saraus, entre outros, além de articular uma programação semanal de visitas dos alunos das escolas do CEU. Vale mencionar que a qualidade do atendimento ao público rendeu a esta biblioteca dois prêmios, um como finalista do concurso nacional Prêmio Viva Leitura de 2012 e outro como vencedora no XI Prêmio de Biblioteconomia Paulista Laura Russo. O organograma de funcionários consistia em uma coordenadora e três bibliotecários. Veremos como, apesar de admitir que o foco do seu trabalho estava no "social", esses profissionais não identificavam a dicotomia usuários/livros acima apontada como estruturadora de seus cotidianos de trabalho. Os espaços internos desta biblioteca estão representados pela perspectiva abaixo, que também deve ser consultada durante as leituras subsequentes. 


\section{perifèria}

Número 19 (1), Juny 2014

revistes.uab.cat/periferia

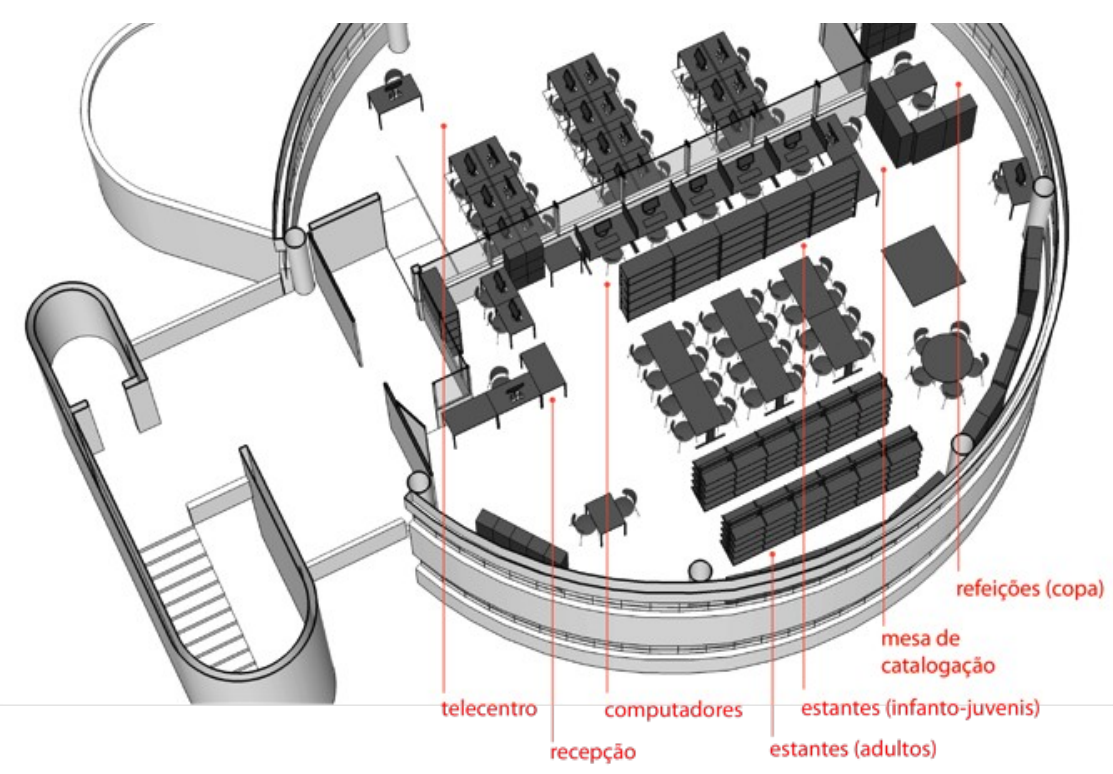

Figura 3: perspectiva da biblioteca do CEU Vila Rubi.

\section{Recepção}
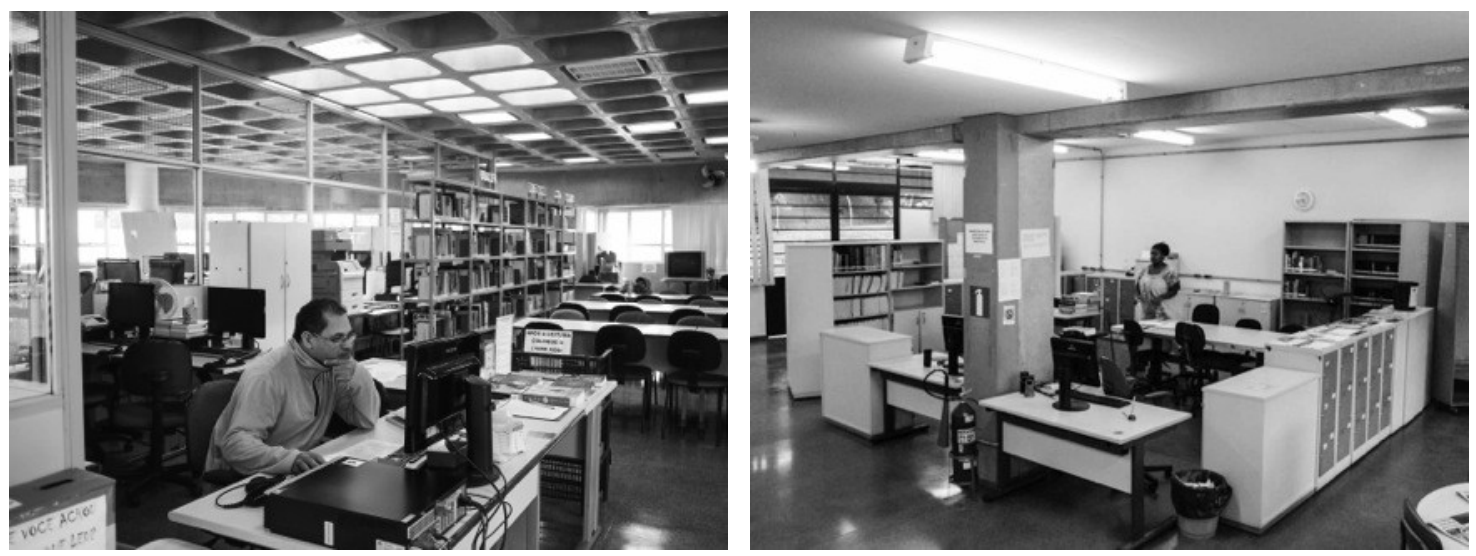

Figuras 4 e 5: espaços de recepção dos CEUs Vila Rubi (à esquerda) e Butantã (à direita).

Passemos agora a problematizar a relação entre espaço e política por meio de uma análise pormenorizada de quatro espaços das bibliotecas, a começar pela recepção. Esse espaço era de preocupação prioritária das bibliotecárias, pois aí se fazia a triagem do que chegava do exterior e do que saía do interior do equipamento. Controles de acesso, cadastros e empréstimos precisavam de contextos intensivos 


\section{perifèria}

Número 19 (1), Juny 2014

revistes.uab.cat/periferia

na forma de normas e espaços, graças aos quais se garantiria a proximidade entre funcionários e usuários.

Nas figuras 2, 5 e 7, relativas ao CEU Butantã, pode-se observar uma série de armários baixos dispostos de modo a configurar um gargalo espacial, com o objetivo de obrigar o visitante a passar em frente ao funcionário da recepção. Esse esforço de indução de interações humanas não se fez necessário na biblioteca do CEU Vila Rubi, certamente porque lá a exiguidade de espaço do equipamento já configurava, por si só, um gargalo - conforme mostra a figura 4 acima.

No âmbito das normas, problemas com cadastro configuravam contextos intensivos que vinham somar-se à intensividade espacial supracitada. Na recepção da biblioteca do CEU Butantã a já mencionada dicotomia entre usuários e livros tomava a forma, por exemplo, da discussão em torno da exigência de cadastro como condição para realização de empréstimos. Por exemplo, quando algumas professoras do CEU participaram de um curso na biblioteca e manifestaram interesse em emprestar alguns materiais, a coordenadora revelou o desejo de realizar o empréstimo sem cadastro. Seu interesse era o de não perder a oportunidade de incentivar a prática da leitura, considerando que o cadastro impediria o empréstimo naquele momento, e que as professoras dificilmente voltariam a procurar a biblioteca no futuro. Este foi um dos pontos de divergência entre ela e outra funcionária, que demonstrou uma maior preocupação para com o controle e a preservação do acervo, sendo contrária ao empréstimo sem cadastro.

Na biblioteca do CEU Vila Rubi, por sua vez, presenciei considerações a respeito da possibilidade de empréstimos de revistas sem exigência de cadastro aos salva-vidas da piscina, sob a justificativa de que eles passariam muitas horas ociosos. Mas as bibliotecárias também atribuíram grande importância ao cadastro, vinculando-o à emissão de uma carteirinha feita sob a condição de apresentação de um comprovante de residência. Assim, foi mais difícil encontrar, nesses relatos, a presença de uma dicotomia entre privilégio a usuários e preservação do acervo.

Passemos a uma discussão em torno de critérios para suspensão de usuários. Certa vez, uma das bibliotecárias do CEU Butantã sugeriu proibir um usuário de realizar empréstimos de revistas depois que ele devolveu um exemplar com a capa rasgada, por tê-lo guardado indevidamente em sua mochila. A coordenadora, por outro lado, procurou observar que a rotina daquele usuário era difícil, que ele tinha problemas de saúde, e que pessoas nas suas condições podiam eventualmente descuidar de precauções com seus pertences. Este seria, a seu ver, o público que o 


\section{perifèria}

Número 19 (1), Juny 2014

\section{revistes.uab.cat/periferia}

CEU deveria atender, e por isso mesmo as normas de uma biblioteca de CEU não deveriam ser aplicadas com rigor. Por outro lado, na biblioteca do CEU Vila Rubi, as bibliotecárias comentaram com naturalidade a solução dada para o caso de um jovem que perdia a capa de uma revistinha: pediam que ele repusesse com outra, trazida de sua casa. O mesmo valia para a perda de livros, e aí não havia preocupação em repor exatamente o mesmo título; ou seja, a preocupação com a reparação do acervo não chegava a ser minuciosa.
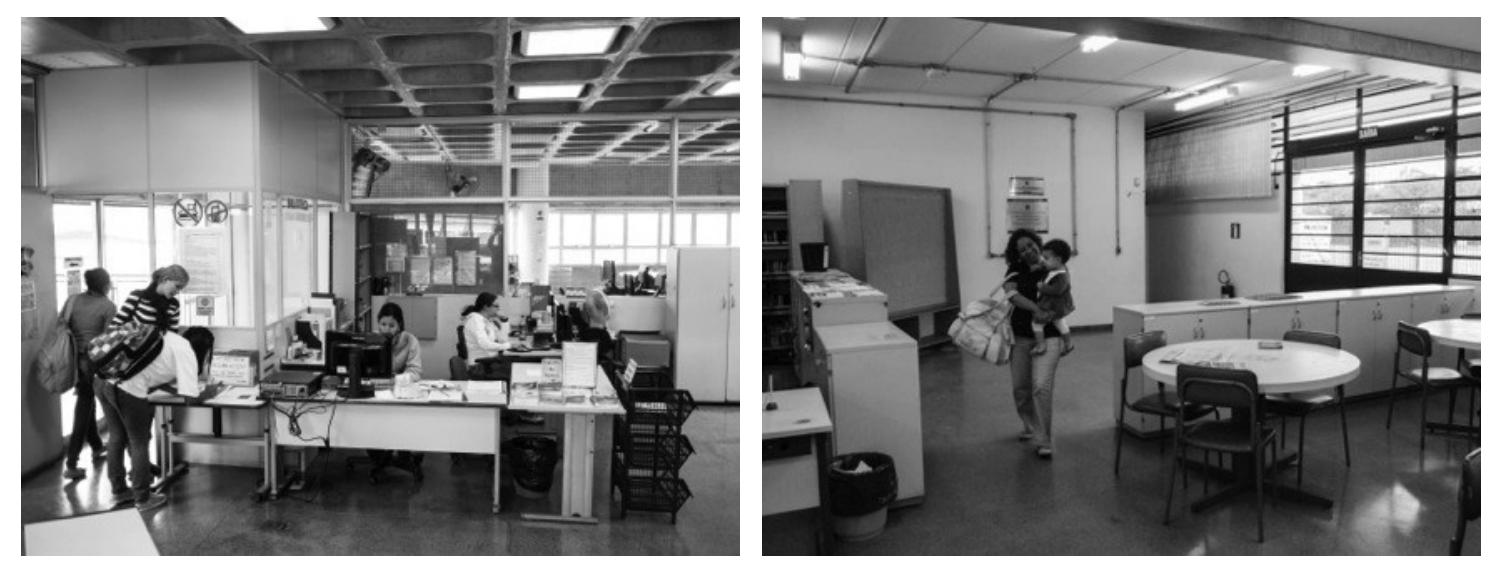

Figuras 6 e 7: controles de acesso às bibliotecas dos CEUs Vila Rubi (à esquerda) e Butantã (à direita).

Tão importante quanto a regulação da saída de acervos era o controle da entrada de pessoas. Nas duas bibliotecas havia uma preocupação com o risco de entrada de formas de sociabilidade conflituosas e assimétricas, frequentes nos ambientes escolares dos CEUs. Certa vez, uma educadora da EMEF do CEU Butantã solicitou à coordenadora que chamasse a atenção de alunos que estivessem "fazendo hora" na biblioteca, demorando para reagir ao sinal de aviso do início das aulas. A coordenadora considerou a atitude sugerida como incompatível com um ambiente de biblioteca. Se esse transbordamento dos códigos de comportamento escolar tendia a ser encarado, no CEU Butantã, como um problema entre funcionários com posições inconciláveis, no CEU Vila Rubi o assunto ganhava conotação mais otimista, mostrando-se como uma questão a ser enfrentada, envolvendo interações entre bibliotecárias e alunos. Para evitar tumultos praticados por alunos das escolas, as bibliotecárias proibiam a entrada de grupos que estivessem em intervalos de aula, porque eles iriam "só para zoar", ficariam correndo, mexendo em vários livros, para logo depois ir embora. As bibliotecárias pediam a esses alunos que viessem antes ou depois do horário de aula, mas permitiam o acesso àqueles 


\section{perifèria}

Número 19 (1), Juny 2014

revistes.uab.cat/periferia

que chegavam com a carteirinha, individualmente, dando mostras de que precisavam retirar livros para realizar trabalhos escolares. Novamente, temos aqui um critério misto, variável de caso a caso, que ora estabelecia regras capazes de proteger o ambiente interno e o acervo da biblioteca, ora reconhecia a necessidade do usuário em detrimento da aplicação da regra.

\section{Computadores}

No CEU Butantã, os computadores localizavam-se numa posição subordinada e periférica em relação ao espaço de leitura, estando mesmo distantes dos olhares das bibliotecárias - como podemos ver na figura 2. É possível que esta distância suscitasse preocupações e estivesse envolvida com certas atitudes inibidoras da utilização destes equipamentos. O relato de um morador de uma comunidade vizinha ao CEU oferece detalhes de como as regras de utilização dos computadores funcionaram como contextos separadores que afastaram usuários do equipamento. O morador alegou a mim ter procurado o computador durante vários dias seguidos, mas em todos eles foram-Ihe exigidos, na recepção, documentos que comprovassem sua identidade, como se ele não tivesse sido visto no dia anterior. Além disso, a bibliotecária da recepção perguntava sobre o propósito de utilização do equipamento, já que no entender de algumas delas o computador de uma biblioteca só poderia ser utilizado para "pesquisas". Em uma das ocasiões, depois de declarar sua intenção de "pesquisar", foi-lhe perguntado o assunto de sua pesquisa, e ele respondeu, já sem paciência, que não sabia o assunto e que justamente por isso precisava realizar a pesquisa. A animosidade entre a bibliotecária e o morador mencionado mostra como as normas de funcionamento configuraram contextos separadores - e não intensivos, como veremos no caso da biblioteca do CEU Vila Rubi - que afastaram certos usuários da biblioteca. 


\section{perifèria}

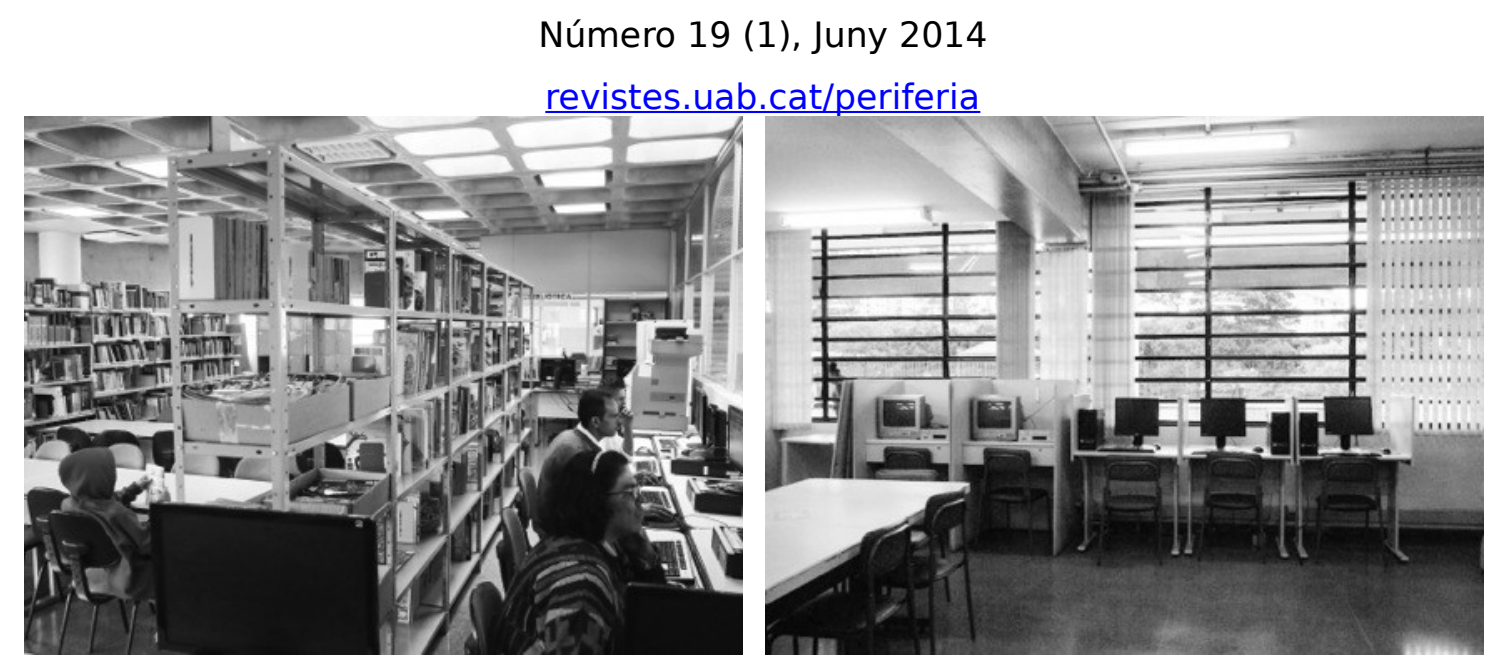

Figuras 8 e 9: espaços dos computadores. No CEU Vila Rubi (à esquerda) as estantes infantojuvenis separam usuários de computadores do ambiente de leitura. A imagem da direita retrata o espaço dos computadores na biblioteca do CEU Butantã.

A biblioteca do CEU Vila Rubi, por sua vez, possuía cinco computadores destinados aos usuários, sendo a utilização e regulação desse uso bastante intensas. O controle era facilitado em grande medida pelo posicionamento de uma série de estantes de livros infantojuvenis logo atrás das mesas com computadores, de modo a formar um estreito corredor, cujo acesso dava-se unicamente por uma passagem lateral à ilha da recepção.

No CEU Vila Rubi, as normas que reforçavam a intensividade espacial do corredor dos computadores eram bastante detalhadas, e poderiam atuar como cerceadoras do uso das máquinas caso as palavras e o tom de voz escolhidos pelas bibliotecárias não transmitissem uma conotação muito diferente daquela praticada por algumas das bibliotecárias do CEU Butantã. Por exemplo, a utilização dos computadores era vetada a usuários com menos de 14 anos, de modo a evitar jogos eletrônicos. Apenas uma pessoa por vez podia usar o computador, já que, de acordo com uma das bibliotecárias, quando dois jovens sentavam-se para utilizar a mesma máquina, havia risco de barulho e confusão. E o tempo de uso era controlado por uma lista de frequência que comumente se transformava em lista de espera.

\section{Estantes}

No CEU Vila Rubi, as estantes estavam localizadas em lados opostos do espaço das mesas de leitura, como mostra a figura 3. De um lado encontravam-se as estantes com conteúdos juvenis e infantis que, como já vimos, separavam os computadores do resto da biblioteca; de outro estavam as estantes com conteúdos para adultos. 


\section{perifèria}

Número 19 (1), Juny 2014

revistes.uab.cat/periferia

Um dos propósitos da separação dos conteúdos das estantes por interesse de faixa etária era inibir tumultos no interior da biblioteca. De acordo com o relato das bibliotecárias, quando as crianças dirigiam-se aos corredores entre as estantes de adultos, ficava evidente que queriam "ficar escondidas" ou "aprontar". Quando advertidos, os usuários costumavam dizer que estavam procurando um livro, e a separação dos conteúdos permitia às bibliotecárias interpelarem as crianças com mais argumentos, já que ali não haveria livros de seu interesse. Mas isso podia ser pouco para contê-las.

Outro recurso considerado insatisfatório pelas bibliotecárias era tentar uma aproximação, pois as crianças ficavam dando voltas ao redor das estantes, sendo impossível alcançá-las: "vira um pega-pega". Nos casos mais complexos, a solução exigia uma medida drástica e efetiva: a bibliotecária trancava a porta da biblioteca, ia até uma mesa de leitura e mandava as crianças se aproximarem, ameaçando mantê-las trancadas ali enquanto ela se dirigisse à diretoria da escola para convocar os pais para uma conversa.
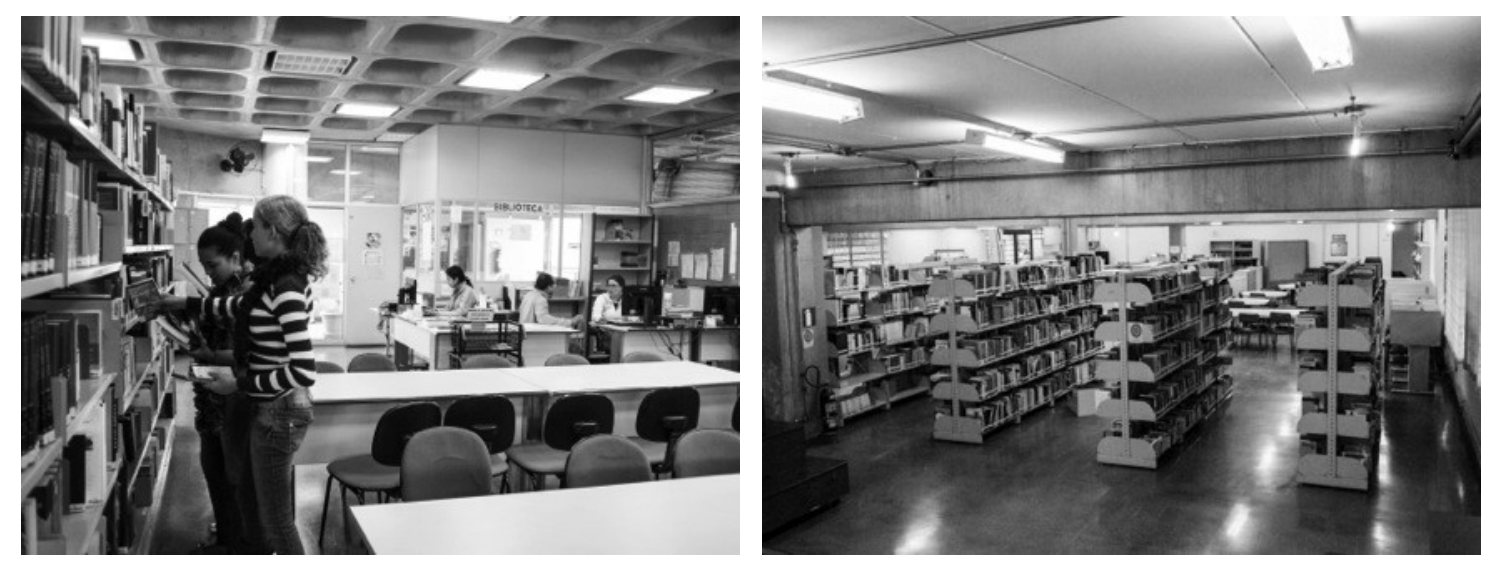

Figuras 10 e 11: estantes. Na imagem do CEU Vila Rubi (à esquerda), vê-se a entrada e a recepção ao fundo. No CEU Butantã (à direita), as estantes formam diversos corredores e caminhos.

No CEU Butantã havia um número maior de estantes, distribuídas de acordo com distâncias e alinhamentos variados, como mostram as figuras 2 e 11. A disposição era considerada confusa por vários usuários e funcionários com quem conversei. Ao tentar explicar o posicionamento das estantes, a coordenadora observou que elas ficaram nos lugares "que sobraram", tendo em vista as necessidades dos outros ambientes. Mas com uma quantidade de espaço tão maior do que aquele disponível 


\section{perifèria}

Número 19 (1), Juny 2014

\section{revistes.uab.cat/periferia}

na biblioteca do CEU Vila Rubi, como se explica o posicionamento das estantes como resultado de uma sobra? Parece claro que, neste nível da análise, não podemos concluir que a área da biblioteca do CEU Butantã era grande, nem em termos absolutos, nem em comparação com a biblioteca do CEU Vila Rubi. O modo como os espaços são praticados e entendidos pelas pessoas é decisivo nesse caso. Desenvolveremos melhor este ponto no próximo item.

Confusões causadas por visitas ocasionais de jovens e crianças também aconteciam na biblioteca do CEU Butantã, mas neste caso não havia soluções evidentes. Pude testemunhar os esforços pouco efetivos de funcionárias que, procurando se fazer ouvir, andavam atrás dos jovens ao redor das estantes, sem conseguir alcançá-los. A ausência de represálias estabelecidas, e, no âmbito do espaço, os caminhos mais longos e variados proporcionados tanto pela amplitude do espaço quanto pelo excesso de corredores entre as estantes, eram fatores que conformavam um contexto extensivo, garantindo aos jovens uma singular facilidade de evitar confrontos com as bibliotecárias. Mas, como vimos, isso também acontecia no espaço exíguo da biblioteca do CEU Vila Rubi, porque a presença das estantes atuava como uma espécie de fator multiplicador do tamanho do espaço, no que concerne às chances de evitar interações interpessoais. Para evitar o confronto com as bibliotecárias, mesmo no espaço de 100 metros quadrados da biblioteca do CEU Vila Rubi, bastava aos jovens darem voltas em torno das estantes. Poderíamos dizer que essa prática de espaço, para os propósitos aqui apontados, equivale a uma prática de fuga em campo aberto; conforme as palavras da bibliotecária do CEU Vila Rubi, "você não consegue alcançá-los". Esse é o melhor exemplo para ilustrar como contextos extensivos podem ser formados não só por lugares amplos, mas também por certas barreiras de espaço.

Na biblioteca do CEU Butantã as dificuldades em lidar com os jovens circulando ao redor das estantes sugerem uma sobreposição de extensividades no âmbito das normas e do espaço. Na biblioteca do CEU Vila Rubi, por sua vez, os fatos acima descritos mostram uma rara dinâmica de interações sucessivas, ao longo das quais contextos diferentes eram acionados em um mesmo espaço e em uma mesma interação: em primeiro lugar, temos um contexto separador de públicos em função da organização das estantes em dois lugares diferentes, por faixa etária. Além disso, as estantes configuravam o contexto extensivo da fuga em campo aberto. Finalmente, a bibliotecária acionava um forte contexto intensivo, fechando a porta da biblioteca para obrigar as crianças a confrontá-la. 


\section{perifèria}

Número 19 (1), Juny 2014

revistes.uab.cat/periferia

\section{Catalogação}

Dentre os trabalhos técnicos de competência de um bibliotecário estão o recebimento, a classificação e a etiquetagem de novas aquisições da biblioteca. A precisão e atenção exigidas por essas atividades podem inspirar preocupações maiores ou menores dos profissionais que as realizam, e essas preocupações alteram significativamente a configuração desses espaços de trabalho.
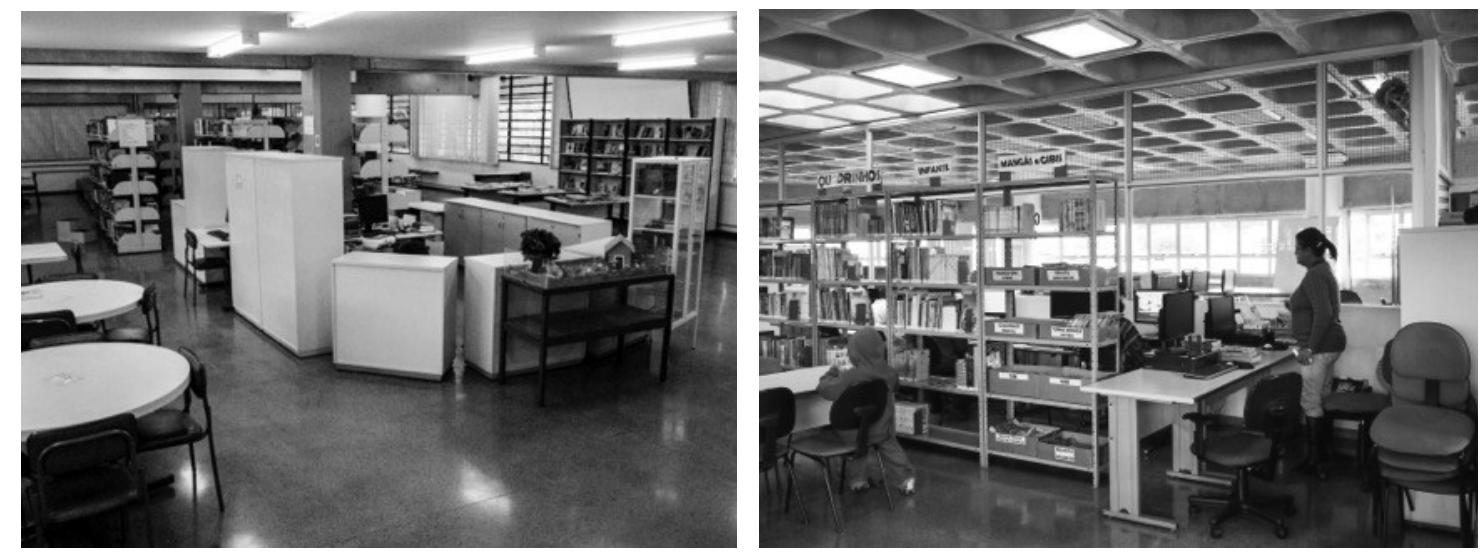

Figuras 12 e 13: catalogação. Na imagem do CEU Butantã (à esquerda), diversos armários formam um espaço separado, tendo as mesas de leitura à esquerda e as estantes ao fundo. Na imagem do CEU Vila

Rubi (à direita), a mesa de catalogação avizinha-se do corredor de computadores e das estantes infantojuvenis.

Na biblioteca do CEU Vila Rubi, uma mesa exclusiva para catalogação foi posicionada nos fundos da biblioteca, procurando um distanciamento máximo do movimento de pessoas da entrada e conformando um tímido contexto separador entre usuários e funcionários. Isso mostra que as separações são importantes para a garantia de privacidade e autonomia de uns sobre outros, e não devem ser consideradas simplesmente como cerceadoras de práticas democráticas.

O trabalho de catalogação na biblioteca do CEU Vila Rubi era de responsabilidade de todos os funcionários, pois eles se revezavam por todas as funções internas da biblioteca, de acordo com uma distribuição semanal de horários. Portanto, todos os bibliotecários exerciam sua parcela de influência sobre a configuração de cada um dos espaços de trabalho. O compartilhamento de tarefas, e o consequente compartilhamento dos lugares em que essas tarefas se realizavam, eram fatores indutores de negociações diversas entre os bibliotecários, formando, portanto, uma 


\section{perifèria}

Número 19 (1), Juny 2014

intensividade.

\section{revistes.uab.cat/periferia}

Já na biblioteca do CEU Butantã havia trabalhos que eram de responsabilidade exclusiva de certas funcionárias. Os lugares destinados à realização desses trabalhos eram predominantemente configurados em função das exigências definidas por essas funcionárias em particular; com o tempo esses espaços terminaram representando essas pessoas, confundindo-se com elas. O fato trazia uma nova camada de significados que vinha se sobrepor de modo complexo àqueles associados mais diretamente às atividades propriamente ditas. Assim, a sala destinada à coordenação da biblioteca era de uso exclusivo da coordenadora e o espaço de catalogação, que nos interessa agora, de uso exclusivo das duas bibliotecárias subordinadas.

A análise realizada das estantes nos levou à constatação de que muitas características objetivas dos espaços podem não ser referendadas pelo modo como eles são praticados ou entendidos. O mesmo acontece com o espaço de catalogação: apesar da amplitude espacial original da biblioteca do CEU Butantã, o espaço de catalogação era visto por suas responsáveis como muito mal localizado, "socado aí no meio". A ilha possuía vizinhos por toda a sua volta, o que dificultaria a realização do trabalho de catalogação, seja pelos riscos de interrupção do trabalho, seja pela necessidade de silêncio e privacidade alegada pelas bibliotecárias subordinadas. Por sua vez, a coordenadora da biblioteca procurava apontar para a necessidade de adaptação às especificidades de trabalho no CEU, lembrando que o usuário "não pode atrapalhar o trabalho, porque ele é o trabalho". Sem aderir a esse raciocínio, as bibliotecárias responsáveis pela catalogação foram agregando armários baixos ao redor de seu espaço de trabalho e substituindo alguns deles por armários altos, de modo a produzir o que chamamos de contextos separadores: foram, assim, "se encastelando" em seus postos, de acordo com uma expressão que evidencia o desdobramento, no âmbito do espaço, das divergências internas e das distintas concepções de serviço público que subordinadas e coordenadora possuíam.

A sala da coordenação funcionava como contraponto ao espaço de catalogação. Segregada dos espaços comuns, era apontada como um privilégio e como um reforço de hierarquias de poder que, aos olhos das bibliotecárias subordinadas, estariam em desacordo com a "filosofia de conversa" que teria orientado a criação dos CEUs. Segundo a visão de uma delas, os CEUs foram criados dentro de um pressuposto de diálogo que ainda não teria se efetivado. Nessa argumentação 


\section{perifèria}

Número 19 (1), Juny 2014

revistes.uab.cat/periferia

vemos uma apropriação bastante particular do tema do acolhimento, que aqui parece entendido como uma forma de questionar hierarquias de trabalho, jogando, se pudermos dizer, os feitiços do acolhimento contra os feiticeiros responsáveis por sua implementação. Na verdade, essa insatisfação particular inseria-se num quadro mais amplo de reclamações de muitos bibliotecários de CEUs com relação à falta de regulamentação e reconhecimento de seu trabalho de um modo geral - fosse por parte dos últimos governos municipais, fosse por parte da Secretaria de Educação, à qual estão subordinados.

A ausência de regulamentações dava grande liberdade aos bibliotecários e poucos mecanismos de cobrança de resultados, configurando um contexto extensivo no âmbito legal. Muitos bibliotecários preferiam afastar-se de suas responsabilidades profissionais como forma de expressar essas insatisfações. Mas trata-se de uma forma de protesto velada e ambígua, sujeita a más interpretações, e que não parecia contribuir para o progresso da deliberação coletiva. Tanto a possibilidade de afastamento quanto sua ambiguidade de sentido aparecem como perigos dos contextos extensivos. Desentendimentos tenderiam a estabilizar os afastamentos, já que haveria poucos fatores indutores de futuras interações. Esses problemas são especialmente proeminentes no caso do CEU Butantã, que possui um acúmulo de extensividades no âmbito do espaço e das normas de funcionamento, ao mesmo tempo que seus funcionários demonstram ter posições antagônicas.

\section{Conjunto dos espaços}

Os fatos observados na biblioteca do CEU Butantã sugerem um processo que começa com a existência de contextos extensivos, capazes de proporcionar tomadas mútuas de distância entre subjetividades dotadas de valores pouco compatíveis. As distâncias reforçaram-se com a posse de ambientes exclusivos, que originaram contextos separadores menores em meio à extensividade inicial. Mas esses ambientes confundiam-se com as subjetividades em interação, ou seja, havia um entrelaçamento entre as identidades de pessoas e lugares, e estes últimos também passaram a entrar em interação de acordo com suas próprias regras e seus próprios recursos. As interações passaram a ocorrer em dois planos simultâneos, distintos e complementares: no primeiro, havia uma extensividade entre as pessoas; no segundo, uma intensividade entre os ambientes, graças às separações responsáveis por sua constituição. Em outras palavras, para a interação entre funcionários, a biblioteca do CEU Butantã possuía abundância de espaço, mas para 


\section{perifèria}

Número 19 (1), Juny 2014

revistes.uab.cat/periferia

a interação entre os ambientes, o espaço era pequeno. Vale observar que a definição do tipo de contexto, em cada um dos dois planos, faz-se em função das características de cada plano e de cada tipo de agente, mas o motor dos processos é o mesmo: são as incompatibilidades de valores que presidem tanto as relações extensivas entre pessoas quanto as relações intensivas entre ambientes. A resultante desse processo era bastante ambígua, e a aceleração proporcionada pela intensividade entre ambientes não parecia ser suficiente para compensar a desaceleração dos contextos extensivos interpessoais. ${ }^{4}$

Um desdobramento importante da intensividade disruptiva entre ambientes consistia nos efeitos da repulsão simbólica e prática exercida pelo espaço de catalogação. Ao seu redor, encontravam-se áreas de aproveitamento difícil para outra atividade que não a circulação, e os ambientes vizinhos sofriam, surpreendentemente, de falta de espaço. Já vimos, por exemplo, como, na fala da coordenadora, as estantes ocupavam os espaços "que sobraram". Somando-se a isso, resgato os depoimentos de dois usuários que reclamaram da falta de espaço no ambiente de leitura, chamando atenção para o barulho produzido pelo bater de cadeiras e mesas em função da movimentação de pessoas ali. A centralidade e preponderância do espaço de catalogação certamente não era o único fator a produzir essas consequências, mas com certeza fornecia uma contribuição importante, sobretudo por se constituir como contexto separador.

Em resumo: na extensividade da biblioteca do CEU Butantã, as separações serviam para reforçar posições e subjetividades antagônicas, que terminavam por criar intensividades disruptivas entre ambientes. Por outro lado, na biblioteca do CEU Vila Rubi, as separações de natureza espacial - estantes, mesas e delimitações de uso dos espaços específicos - atuavam como articuladoras da pressão interna típica de contextos intensivos. Por isso, essas separações tinham uma função crucial, combinando-se de forma importante com contextos intensivos espaciais - formados principalmente pela exiguidade dos espaços - e legais - por meio de uma proliferação de normas e regras exercidas no sentido de promover o acolhimento, como vimos acima.

4 Esta explicação traz implícito um possível desdobramento para o que propomos chamar de teoria dos contextos. As subjetividades ou agências que atuam no palco definido pelos contextos não precisam necessariamente ser pessoas ou passar decisivamente pelo estilo de sua agência. No caso da biblioteca do CEU Butantã, os ambientes de trabalho eram atravessados por agências tanto quanto os corpos humanos, e cada um desses tipos de agente possuía sua própria dinâmica. A agência poderia passar também por outros objetos e lugares, de escalas variadas, e ainda assim os três tipos de contexto poderiam oferecer uma forma útil de classificar os constrangimentos que estariam presentes em cada caso. 


\title{
perifèria
}

\author{
Número 19 (1), Juny 2014 \\ revistes.uab.cat/periferia
}

\section{Conclusões}

As análises precedentes indicam que a presença ou ausência de posicionamentos antagônicos organizou-se nas bibliotecas dos CEUs analisados em função do par usuários/livros: na biblioteca do CEU Butantã o privilégio a um desses termos excluía o privilégio ao outro, enquanto na biblioteca do CEU Vila Rubi as duas dimensões apareciam como importantes e compatíveis.

Parte da explicação dessa diferença parece residir na alta prescritividade com que o acolhimento foi defendido durante a implementação dos primeiros CEUs. Pelo menos no caso do CEU Butantã, a defesa veemente do acolhimento fez-se em conjunto com a desqualificação de outras práticas e atores, assim transformados em antagonistas. Nesse sentido, talvez possamos dizer que o acolhimento produziu seus próprios inimigos, num processo semelhante ao que Taussig (1993) encontrou quando considerou que os colonizadores espanhóis terminaram por criar o xamanismo durante a colonização da América Espanhola. Por sua vez, o CEU Vila Rubi, de história mais recente, passou ao largo dessa dicotomização de posicionamentos.

Quanto à influência do espaço na política do cotidiano, problematizamos o valor invariavelmente positivo que costuma ser dado à abertura espacial, relativizando sua associação unívoca a práticas democráticas. Propusemos, em seguida, a ideia de contextos separadores, intensivos e extensivos. Pelo que as análises acima sugerem, um contexto extensivo pode colocar ao alcance das pessoas a escolha por interagir, e com isso é possível associar essa extensividade a práticas democráticas. Mas, em outro sentido, e especialmente em interações dominadas por antagonismos importantes, a extensividade pode ser inibidora ou desaceleradora de deliberações coletivas. Talvez seja possível afirmar que, num contexto extensivo, desacordos podem gerar afastamentos, que por sua vez tenderiam a estabilizar os desacordos. Confusões de sentido e estigmatizações interpessoais podem proliferar com mais facilidade, tendo em vista o fato de que as pessoas deixariam de interagir e de atualizar o seu ponto de vista a partir do ponto de vista das outras. Por sua vez, em dinâmicas intensivas as pessoas precisariam interagir, e se isso não necessariamente induz ao surgimento de consensos, certamente representa um incentivo para a realização de um cotejamento mais intenso de pontos de vista. Portanto, para este caso, talvez possamos falar de uma aceleração da dinâmica política e das interações interpessoais. Finalmente, contextos separadores podem 


\section{perifèria}

Número 19 (1), Juny 2014

revistes.uab.cat/periferia

ter usos diversos, garantindo a posse de recursos e espaços, regulando acessos e trocas interpessoais, reforçando a autonomia e a subjetividade de sujeitos e grupos.

Poderíamos sugerir uma conclusão que, perto da riqueza dos fatos encontrados, pareceria de uma generalidade um tanto grosseira, e que qualificaria, de um lado, o contexto do CEU Butantã como extensivo, e, de outro, o contexto do CEU Vila Rubi como intensivo - com os contextos separadores atuando como agentes moduladores dessas tendências dominantes. Mas parece mais importante mostrar que, dentro de cada CEU, podemos encontrar diversas produções de contextos. Esses contextos podem desenvolver-se em escalas diferentes - entre funcionários, entre usuários, entre ambientes, entre equipamentos, entre o CEU e seu entorno -; em meios diferentes - configurações espaciais, normas de utilização, entre outros -; e podem relacionar-se de modos diversos, ora contrapondo-se, ora reforçando-se, ora imbricando-se com problemas de outras ordens. ${ }^{5}$ Esta pesquisa sugere a possibilidade de estudar as interações políticas cotidianas, intervindo nelas de acordo com uma combinação oportuna de contextos.

\section{Bibliografia}

Caldeira, Teresa P. do R. (2000). Cidade de muros: crime, segregação e cidadania em São Paulo. São Paulo: Ed. 34, Edusp.

Corbioli, Nanci (2008). "Nova proposta para o CEU revê conceito e desenho original". In: ProjetoDesign, n. 342, ago. 2008. [on-line]. Disponível em: $<$ www.arcoweb.com.br/arquitetura/makhohl-arquitetura-centro-educacional-10-092008.html>. Acesso em: 20 jun. 2014.

Dale, Karen \& Burell, Gibson (2010). "'All together, altogether better': the ideal of 'community' in the spatial reorganization of the workplace." In: Marrewijk, Alfons van \& Yanow, Dvora (eds.). Organizational Spaces. Rematerializing the Workday World. Cheltenham, UK, Northampton, USA: Edward Elgar Publishing Limited.

Doria, Og Roberto (2007). Educação, CEU e Cidade: breve história da educação pública brasileira nos 450 anos da cidade de São Paulo. São Paulo: Secretaria Municipal de Educação de São Paulo.

5 Seria importante entender a influência dos contextos dentro de um conjunto mais amplo de condicionantes - de ordem social ou cultural, territorial ou local. No entanto, mesmo que o espaço deste artigo tivesse nos permitido uma análise mais ampla, nossas conclusões, para a problematização do que chamamos de contextos, não seriam afetadas significativamente. 


\section{revista de recerca i formació en antropologia}

\section{perifèria}

Número 19 (1), Juny 2014

revistes.uab.cat/periferia

Ferraz, Marcelo Carvalho (coord.) (1997). Vilanova Artigas: arquitetos brasileiros Brazilian architects. São Paulo: Instituto Lina Bo e P. M. Bardi, Fundação Vilanova Artigas.

Freire, Paulo (1968) [2011]. Pedagogia do oprimido. Rio de Janeiro: Paz e Terra.

Geertz, Clifford (1983). "'From the Native's Point of View': On the Nature of Anthropological Understanding". In: Local Knowledge. New York: Basic Books.

Padilha, Paulo Roberto; Silva, Roberto da (orgs.) (2004). Educação com qualidade social: a experiência dos CEUs de São Paulo. São Paulo: Instituto Paulo Freire.

Sennett, Richard (1974) [1988]. O declínio do homem público: as tiranias da intimidade. São Paulo: Companhia das Letras.

Taussig, Michael (1993). Xamanismo, colonialismo e o homem selvagem: um estudo sobre o terror e a cura. Rio de Janeiro: Paz e Terra.

Warren, Mark E. (2001). Democracy and Association. Princeton, USA, Oxford, UK: Princeton University Press.

Williams, Richard J. (2009). Brazil - Modern Architectures in History. London:79 Reaktion. 